
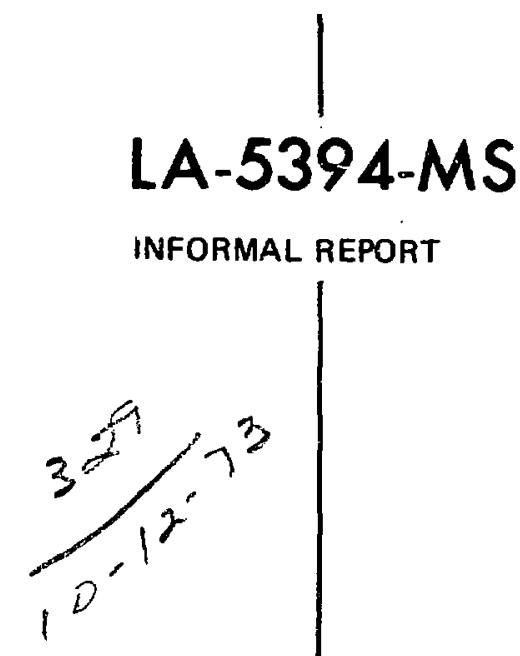

Arithmetic Box for Enrichment Meter and Neutron Assay Instruments 
This report was prepered as an eccount of uork sponsored by the United Stutes Government. Neither the United Stutes nor the United Stotes Atomic Energy Commission, nor any of their employees, nor any of their contrac. tors, subcontractors, or their emplovees, makes any warranty, expess on im. plied, of assumes any legal liability or responsibility for the accuracy, com. pleteness or usefuiness of any information, apparatuz, product or process dis. closed, or represents that its use would not intringe privately owned rights.

In the interest of prompt distribution, this LAMS re. port was not edited by the Technical information staff.

Printed in the United States of America. Available from National Technical Information Service

U. S. Oepartment of Commerce 5285 Port Royal Rasd Springlield, Virginis 22151

Price: Printed Copy \$1.00; Misrofithe $\mathbf{5 0 . 9 5}$ 


\section{LA.5394-MS \\ Infomal Report \\ UC-15}

1SSUED: Seprember 1973

\section{Arithmetic Box for Enrichment Meter and Neutron Assay Instruments}

by

E. R. Martin

T. R. Ven Lyad

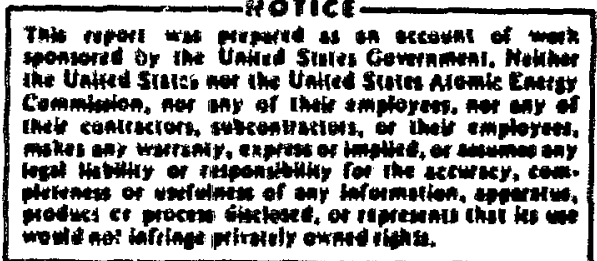

of the Universily of Callfornie

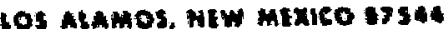

$f$ 


\title{
GRITHMETIC BOX FOR ENRICHMENT METER AND NEUTRON ASSAY INSTRUMENTS
}

\author{
by
}

E. R. Martin and T. R. Van Lyussel

\begin{abstract}
Thte report documents the construction and operation of the arithmetic unli developed by Group A-1 for use with the gamma enrichment meter and the neutron monitor nondesitructive assay oystems. The generle equation, ASSAY $=A \cdot C_{1}-B \cdot C_{2}-D$, is solved automatically on line whlle the datu are being taken; the tinal answer ts presented directly on LED displays; and the tine of day, staler counts, and Itnal answer are also printed on a teletype unit.
\end{abstract}

\section{INTRODUCTION}

The ceneric equation, ASSAY $=A \cdot C_{1}$ - B. $\mathrm{C}_{2}-\mathrm{D}$, oceurs trequently in the course of nondentructive monitoring of Iisstonable materials by the enrichment meter instrument or nevtron counting. Group A-I has designed and reported in detau ${ }^{1}$ the princtples behind ingtrumentation which permits direct calculation of this equation whlle the date are being retelved. This report will serve to document the construction and operation detalis of an arithmetic unlt butit by Group $\Lambda-1$ to tmplement these principles. The rack-mountable tut descrtbed here is relatively inexpensive, reliable. and aimple to operate, replacing two scalers, a time-of-day and day-of-year clock and calendar, a teletype interface, two discriminators, and a great deal of tedious hand calcutation.

\section{PHYSICAL DETAILS}

The finfsheo unit is shown in Figs. 1, 2, and 3, which show the front, back, and top vitews respectively, indicating cleaply the basto elements of construction. As is apparent, we have chosen to impleinent the slectronics on small prtited curcult cards, which permit simpler masa production, ragid debugging, and easter troubleshooting and repair. Our unit was conetructed to be rack-mountable, aince tt will be ured in conjunction with equipment not normally portable in operation. It derives stg power from the atundard 115-voll ac power line, and ts capable of driving several teletypes in parallel through cables up to several hundred feet in length. Clearly, this unit will find applfanton in fixed polmt situattone where long data runs with hardcopy output are being made. Severat identical units could be used, for example, in the "hyl 1 " counter aystem, where one unit would be used with the gamma monitor and the other whth the neusron instrument. The unit ts entirely self-contalned and requlres only power connections and a teletype for complete operation. 


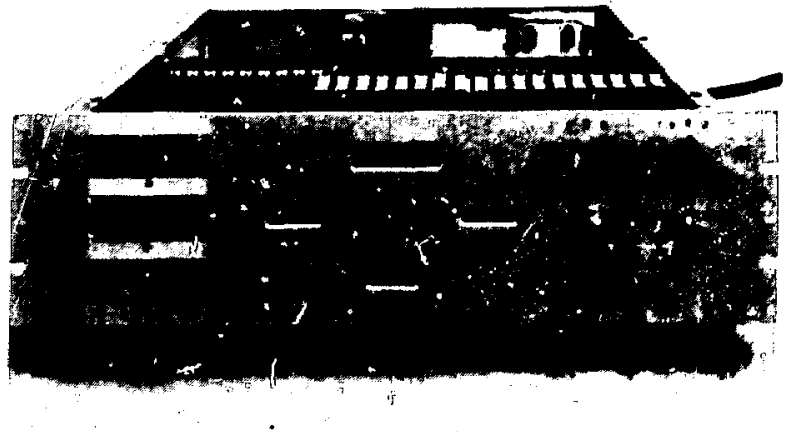

Fig. 1. Front view of arithmetic unit.

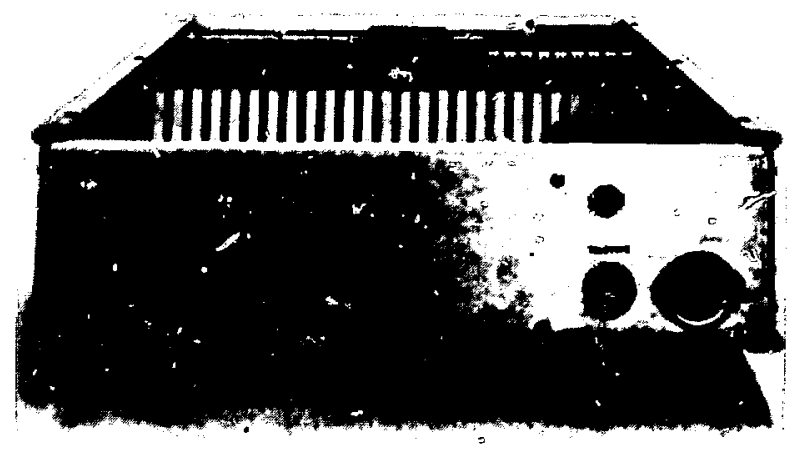

Fig. 2. Back view of arithmetic unit.

\section{II. ELECTRONIC DETAILS}

The schematic detalls of individual printed circuit boards are shown in Figs. 4 through 16. Figure 4 is the input circuit. Three input modes are switch selectable from the front panel as shown in Fig. 1. In mode 1 the input is directed into a discriminator which will discriminate positive input signals down to 100 millivolts. This diserimination level is screwdriver adjustable from the back panel (F ig. 2) for each of the two input channels. Made 2 expects positive-going 0 - to 3-volt

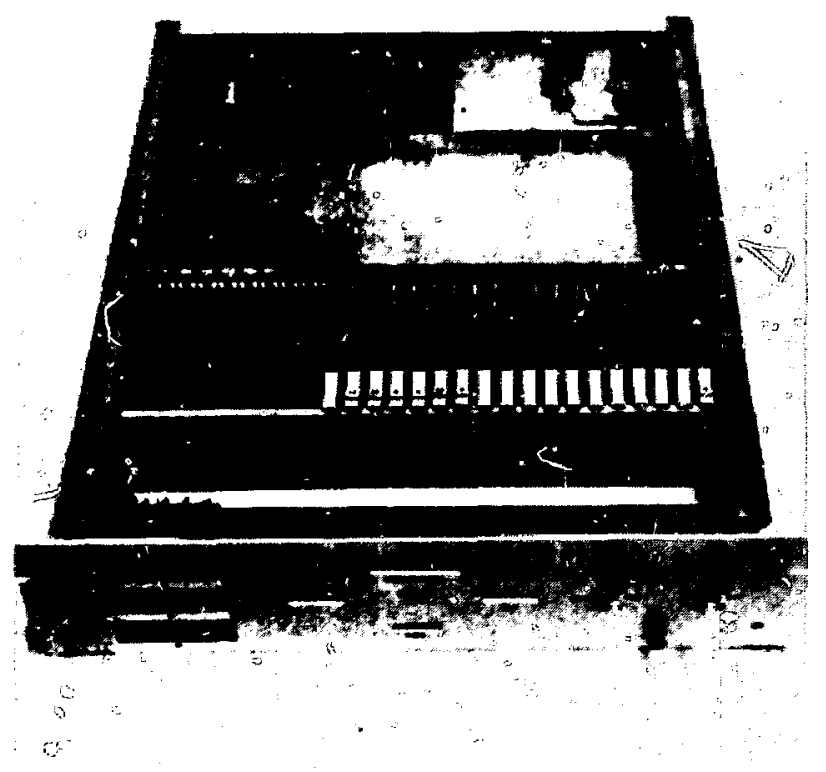

Fig. 3. Top view of arithmetic unit.

input signals of arbitrary length. Mode 3 is simply reverse polarity from mode $2 ; i$. e., negativegoing 3- to 0-volt pulses are accepted. Note that the risetimes of these input puises are not critical since signals are received in the unit by Schmitttrigger circuits. Both inputs are terminated in 50 ohms to eliminate line rin ing and noise assoctated with high-impedance circuits. If datsy-chaining of the input signal is desired with the termination elsewhere, the 51-ohm input terminator can easily be removed, yielding an input impedance over $1 \mathrm{k}$.

Figure 5 shows the scaler with input gating. Two of these boards are used for each input channel, providing six-digit capacity for each scalez. Each of these six-digit scalers is provided with its own LED display as shown in Fig. 1. These scalers du not contribute in any way to the calculated answer, but serve merely to indicate to the 
user when counts are being received, and to permit simpler calibration on known standards. The " $\mathrm{X}$ out" signal f. om these scalers is routed into the digital rate multipliers for on-line multiplication by tne selected constants.

$F$ igure 6 shows the detalls of the digital rate multiplier circuit, which is quite straightforward. The numbered input lines to the SN74167 integrated circinits conse from the thumbwheel switches on the front parel of the unit for constants $A$ and $B$. These thumbwheel switches are used for setting in the $A$ and $B$ multipication constarts in the calculation. Constant $D$ is set into the up-down counter (Fig. B) in a manrer to be described presently. The number of output signals from this multipler circuit is equal to the number of input signals multiplied by the constant set into the thumbwheel swisches and divided by ten.

The up-down counter for each channel is also a six-digit scaler consisting of two boards for each channel. Ench board to constricted according to the diegram of Fig. 7. The preset inputs to this acaler are not used in this equfpment, but are brought out on the board for general purpose use elsewhere. For our use, the "load" input is grovided, and "carry" and "borrow" lines are provided for cascading purposes. Note that the data lines are a four-wire data bus with wire-ORed connections to individual decades.

Figure 8 is a ingle-board six-digit updown counter with zero detect output. The general logte dlagram of the arithmetis unit shows that the down counting operation is stopped at the correct answer when the multiplted inputs of channel $B$ are counted to zero. This board provides the stop signal for the down coun:. It is here also that the constant $D$ is set into the system. The prestet lines on the SN74182 ICs are used for this purpose, with the thumbwheel awltches provlded on the front panel for operator ease in changing constants. The "load" pulse is used as a strobe pulse for this coristant, so that it is set into the counter at the commencement of each counting interval. Since this counter will be zero at the end of the calculation, it is not necessary to bring out its data lines.

Resetting after a counting interval has been completed and the data printed out can be accomp2:shed in two ways: (1) if the automatic mode is chosen (see front panel mode switch in Fig. 1), another counting interval will be started automatically after the data printout on the teletype, sothat contintrous runs can be made without operator intervention: (2) if the switch is in the manual position, the ruset pulse will be generated only when the operator preases the "reset" button. Figure 9 shows the distalls of this circuit. The "Bhift". "sr clr". "sr out", and "8r clk" pulses are asaocinted with the teletype interface in a manner which will become apparent as we turn attention to the detalls of the teletype-driving circuitry.

The time-of-day clock shown in Fig, 10 to self-explanatory, except perhape for the strobe delay generated by the Sivi123. Thto la necessary because of the very slow risetime of the MOS output pulses from the clock chy, since the hours ten digit is used for incrementing the day counter 28 each 24-hour period elapses. The clock has its own front panel display (Fig. 1 ) and its own setup switches on the back panel (Fig. 2). Since it is desired to print out on the teletype this timeof-day information for each andyas interval, tt Is necessary to gate and atore the day information to prevent possible ambiguous date from being printed. This function to performed by the board detalled in Fig. 11.

The day-of-the-year celiendar simply atores for printout the number of the day of the year. It consiats of a 3-stage sealer shown in Fig. 12, whtch is increntented as each 21-hous period expires, or can be incremented manually by a pushbution switeh on the back panel for initial setup. Once again, the output from this counter goes onto the common date bus as shown. 
The interval tiner shown in $F i g .13$ permits the operator to choose intervals of one, two, or five minutes duration as shown in Fig. 1. We used a crystal oscillator (C0238) operating at $8 \mathrm{MHz}$ for this interval timer, since the short-term accuracy of the ac line frequency is not good enough for interval timing on a very accurate measurement. This timex provides input gating as well as down counting for the final calculation. The detailed drawing of the circuit makes its operation fairly apparent.

The teletype interface is shown in $\mathrm{F}^{2} \mathrm{z}^{5} .14$, 15, and 16. It is a straightforward parallel-toserial interface. Worthy of mention, perhaps, is the fact that the oscillator period specified in Fig. 14 is for the standard 110-baud data transfer to a
Teletype Model 33 printer. This frequency is easily changed for other printing units by simply changing the value of the 33-microfarad tantalum capacitor and readjusting the 500-ohm potentiometer on the board.

\section{ACKNOWLEDGMENTS}

The authors are indebted to many Group A-1 members for discussions which led to the development of this instrument. In particular, Joerg Menzel prowided the impetus for actually constructing this unit by testing a prototype in field operations. Apprectation is also expressed to David F. Jones for much help with circuit details and cabugging. The interval timer is his.

\section{REFERFNCES}

1. E. R. Martin, "A Direct Reading Artthmetic Unit for NDA of Nuclear Materials, "Nucl. Insi. \& Meth. 109. p. 439 (1973).

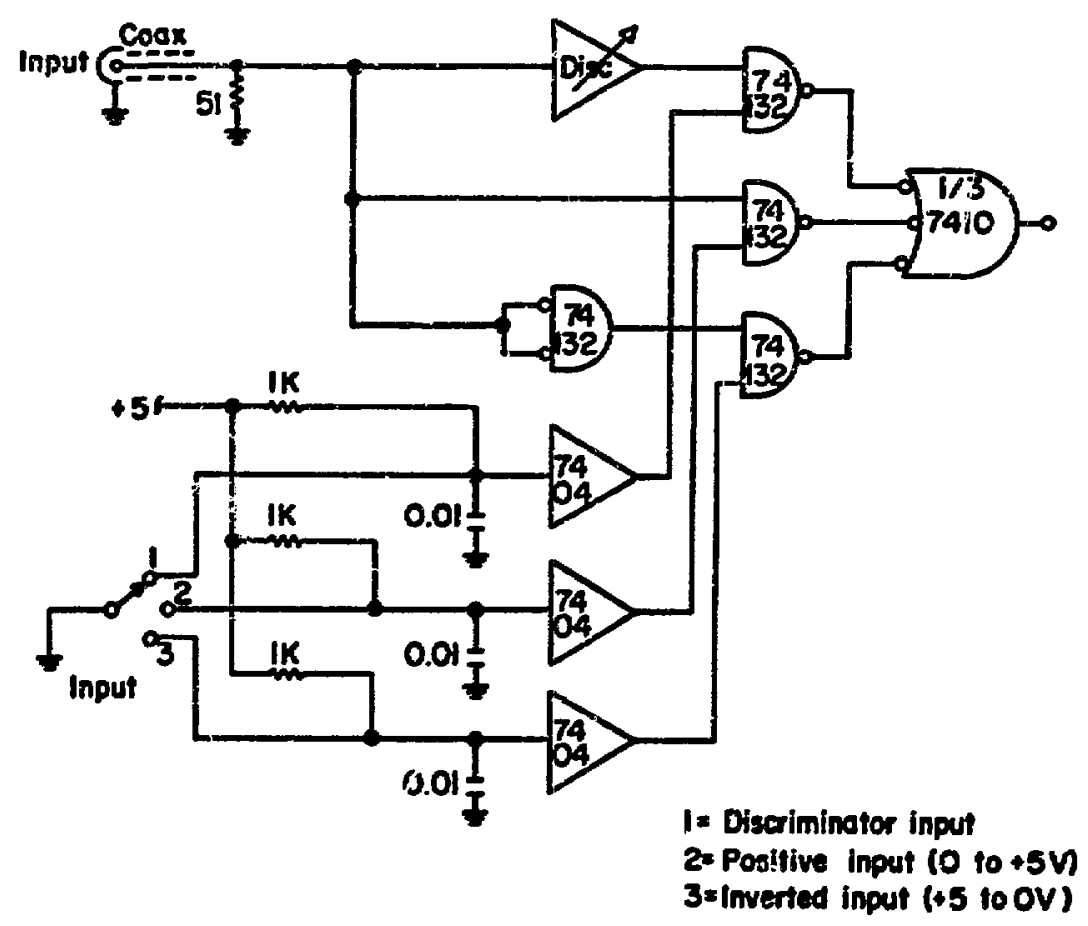

Fig. 4. Input Circult. 


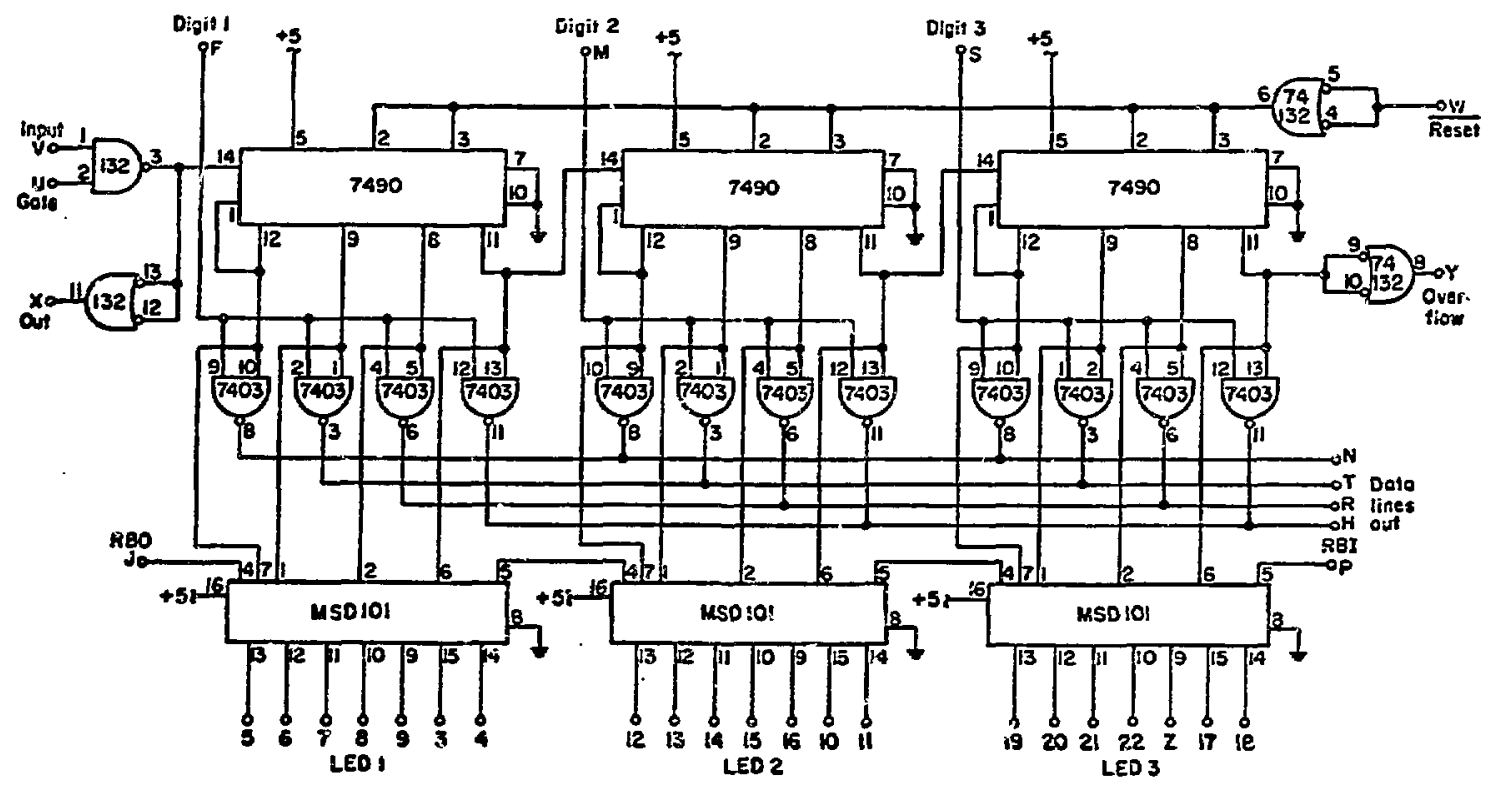

Fig. 5. Three-Decade Scaler.

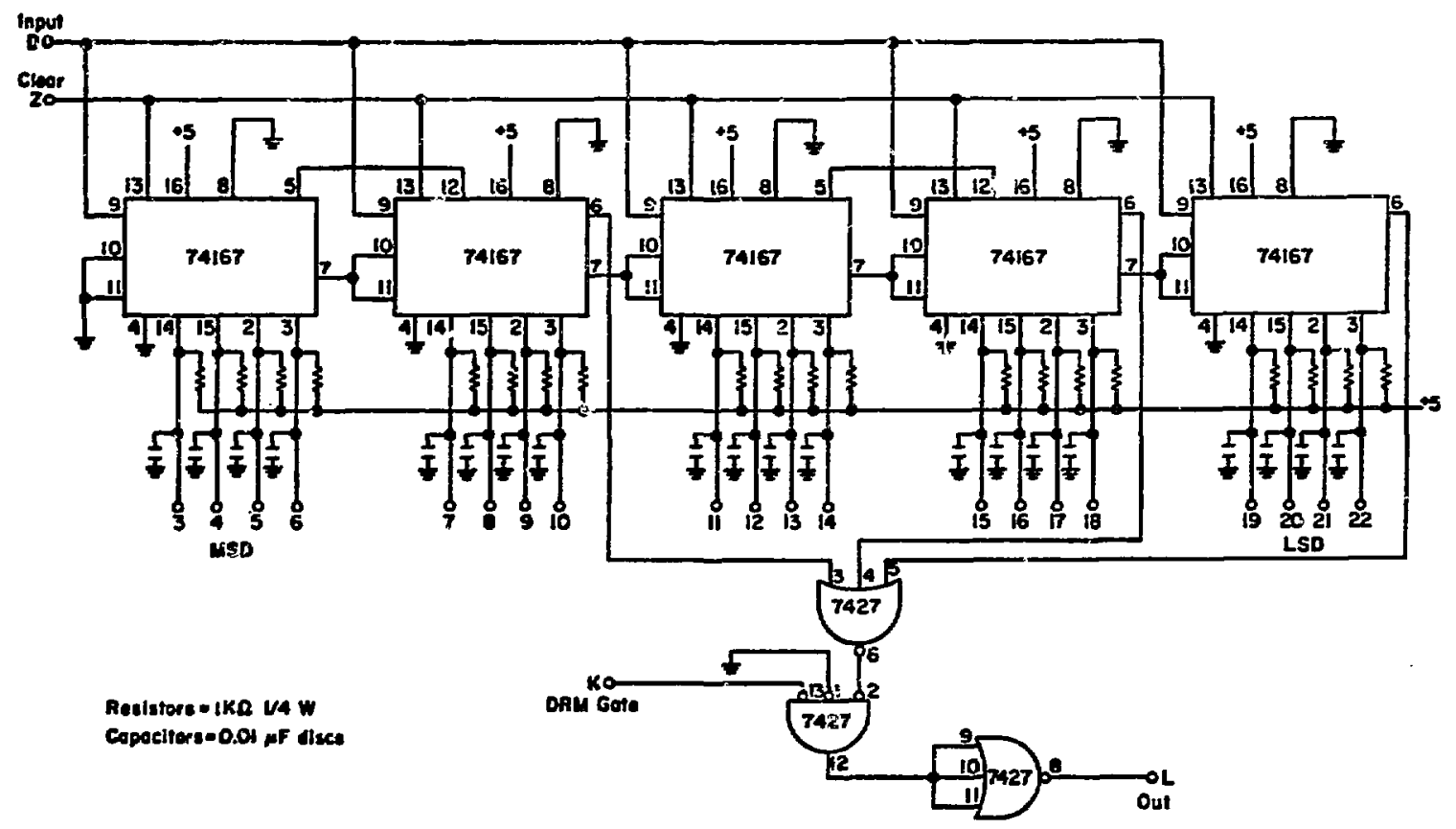

Fig. 6. Multiplier Circuit. 


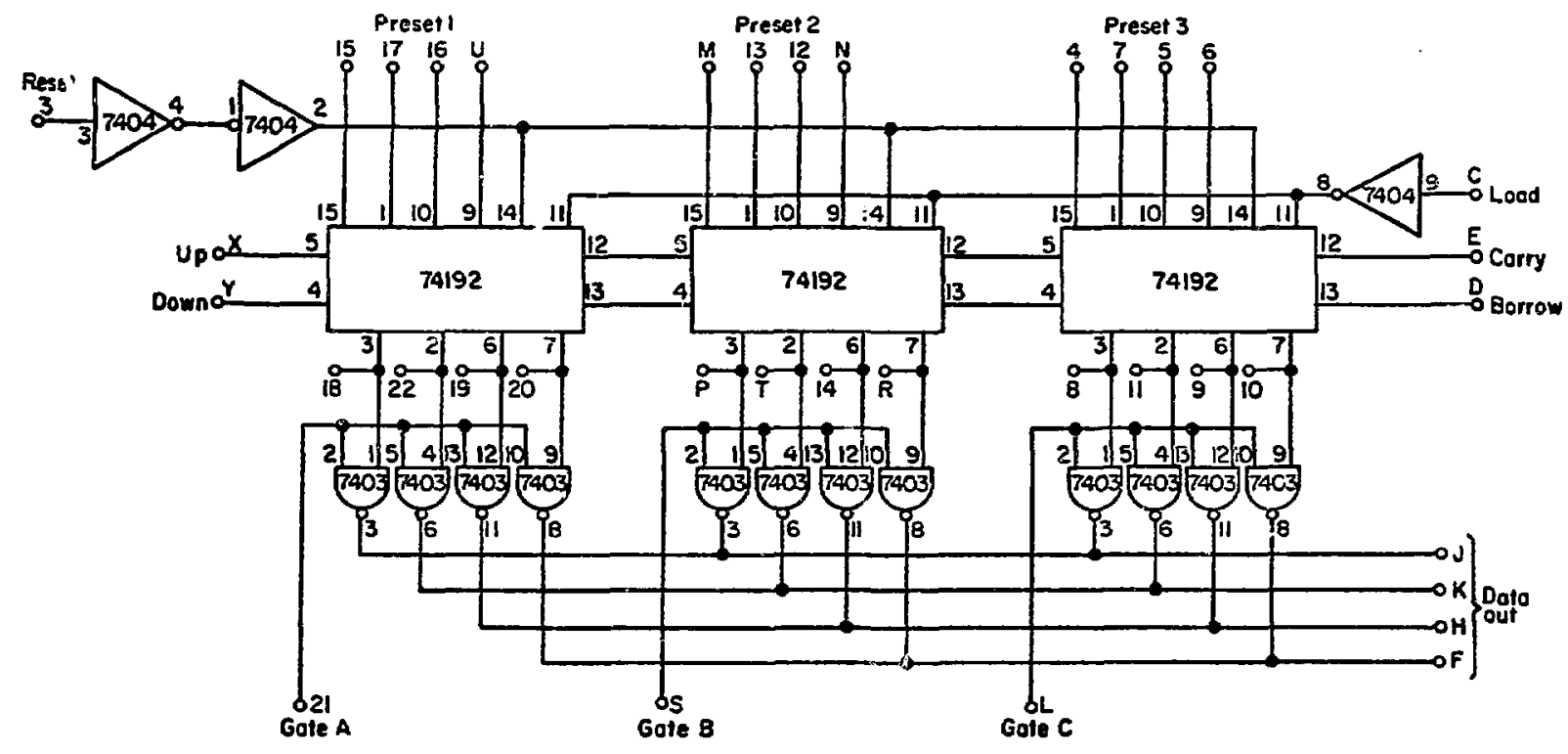

Fig. 7. Up-Down Counter.

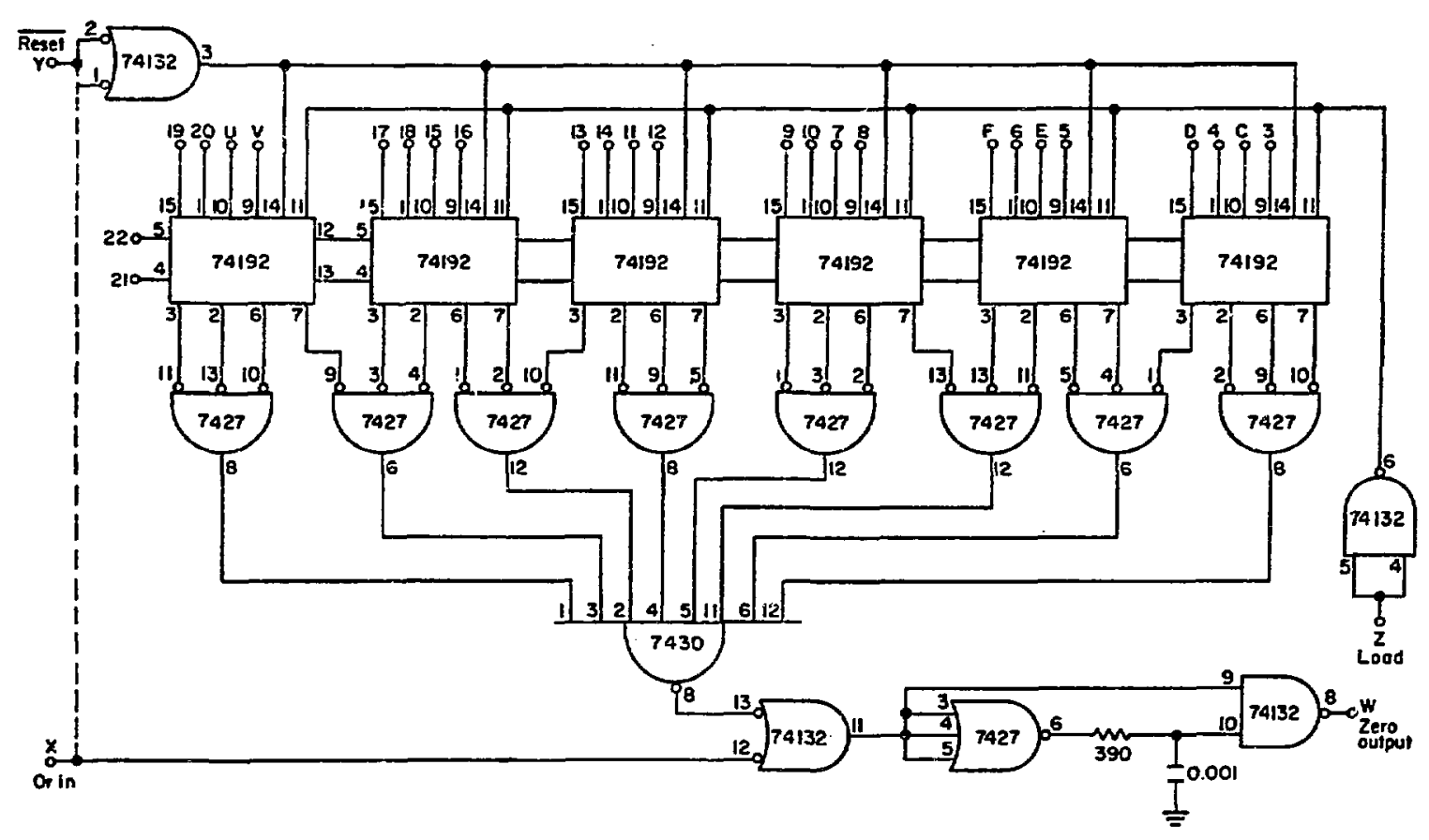

Fig. 8. Up-down counter with zero detect. 


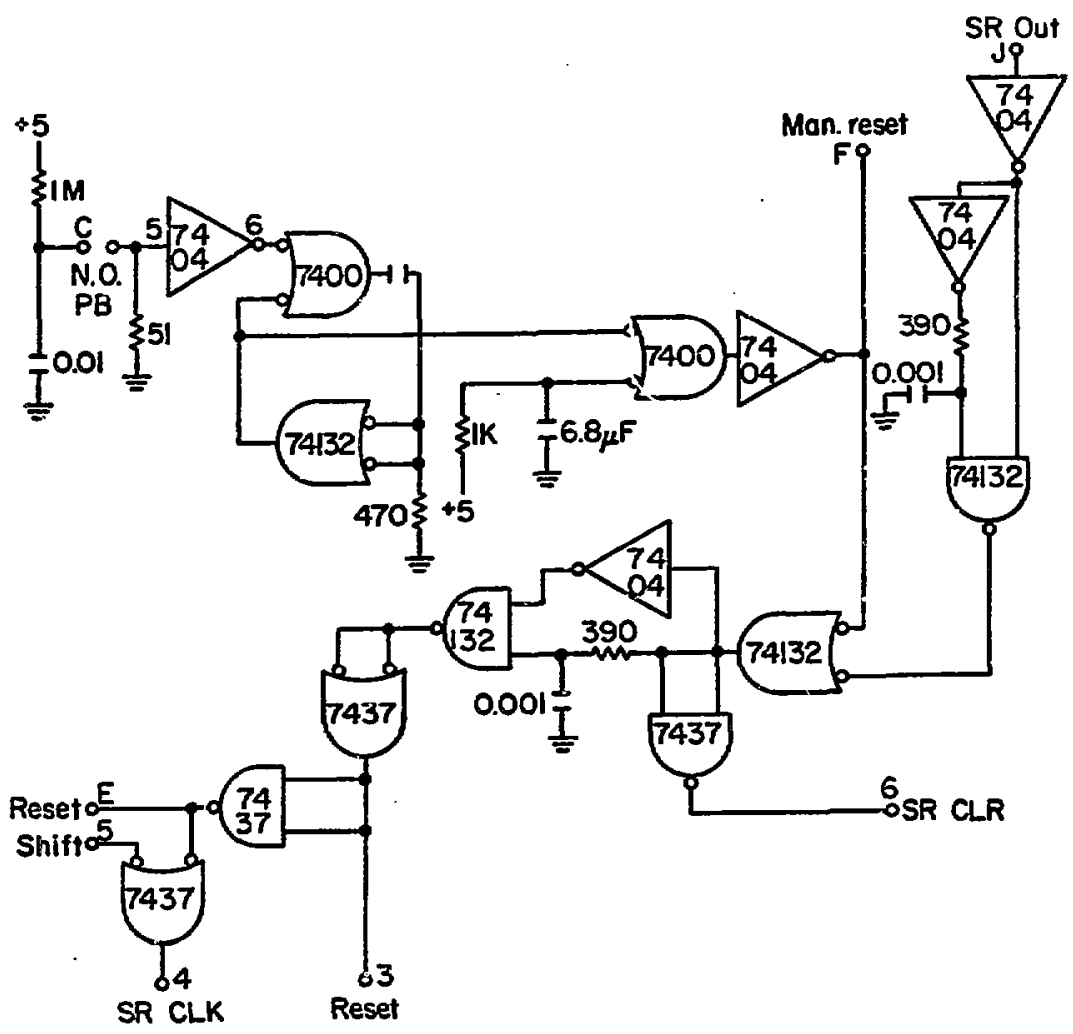

Fig. 9. Reset Circuit.

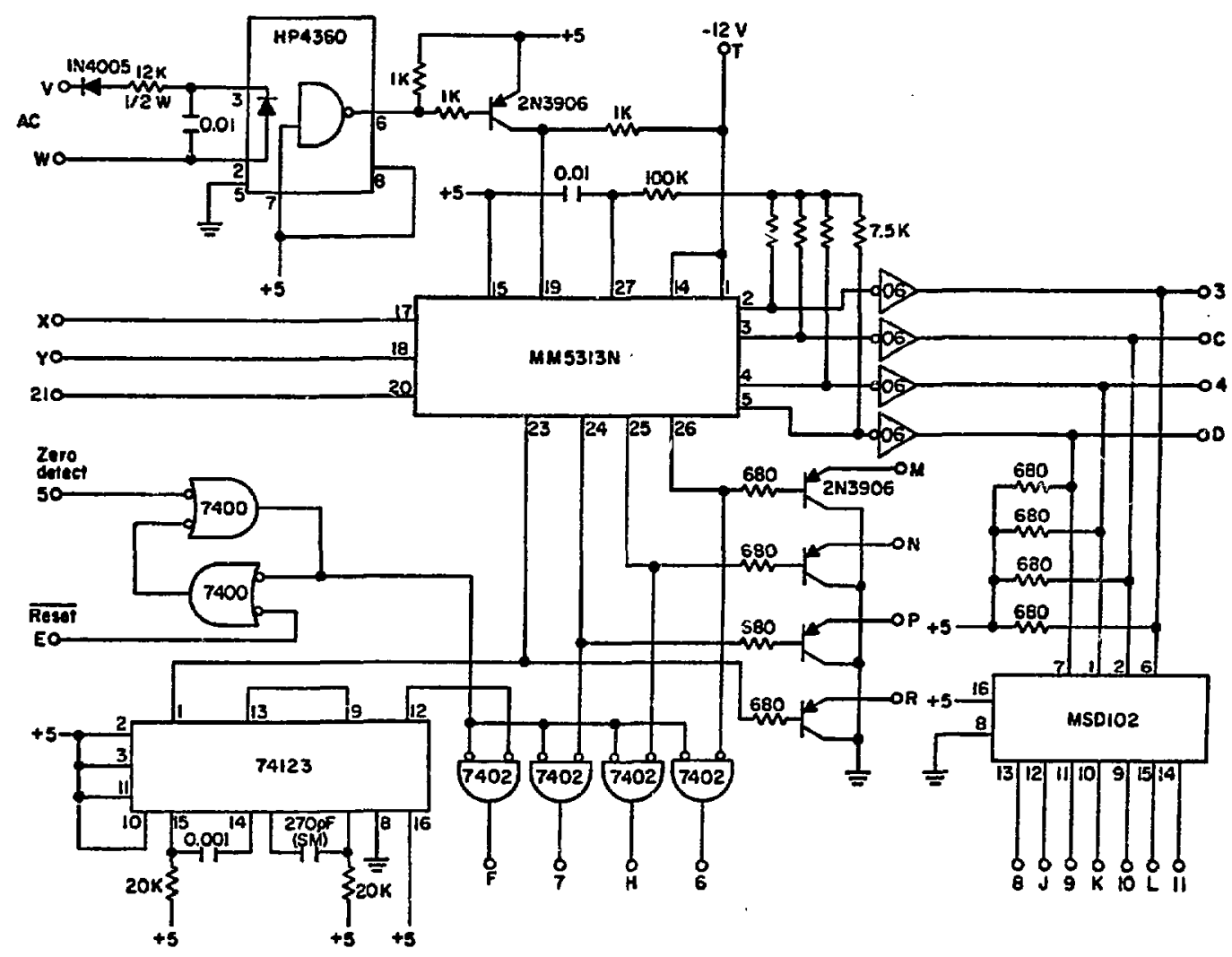

Fig. 10. Time-of-Day Clock. 


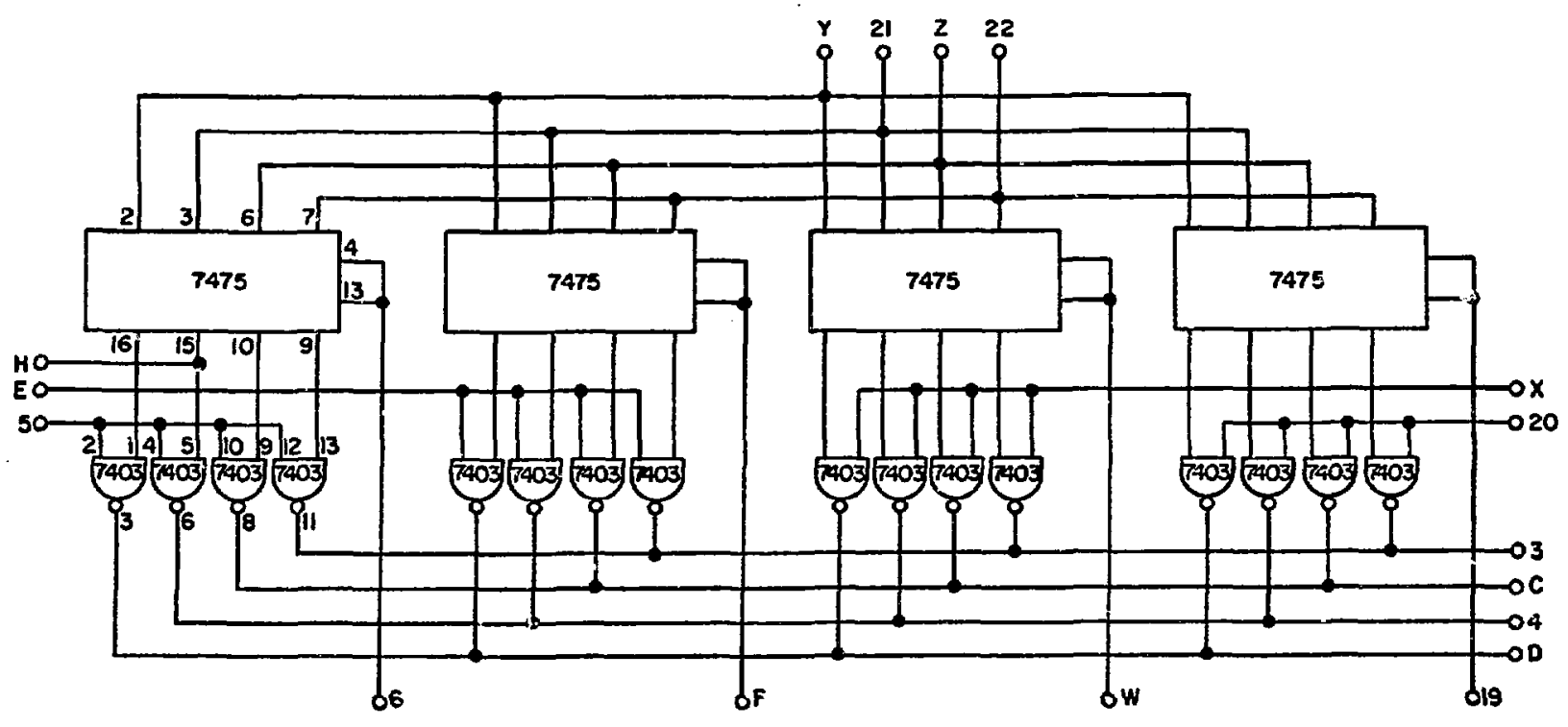

Fig. 11. Time-of-Day Data Latches.

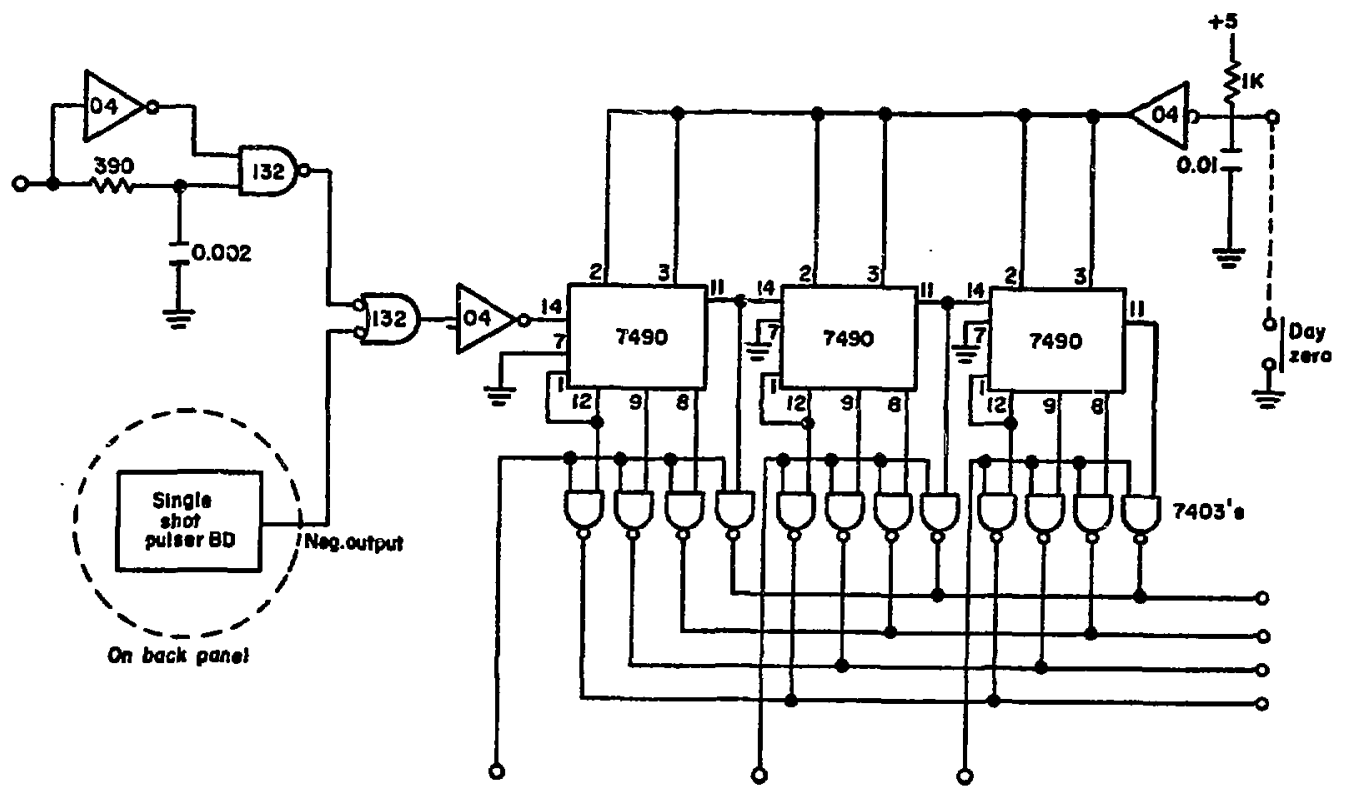

Fig. 12. Day-of-Year Calendar. 


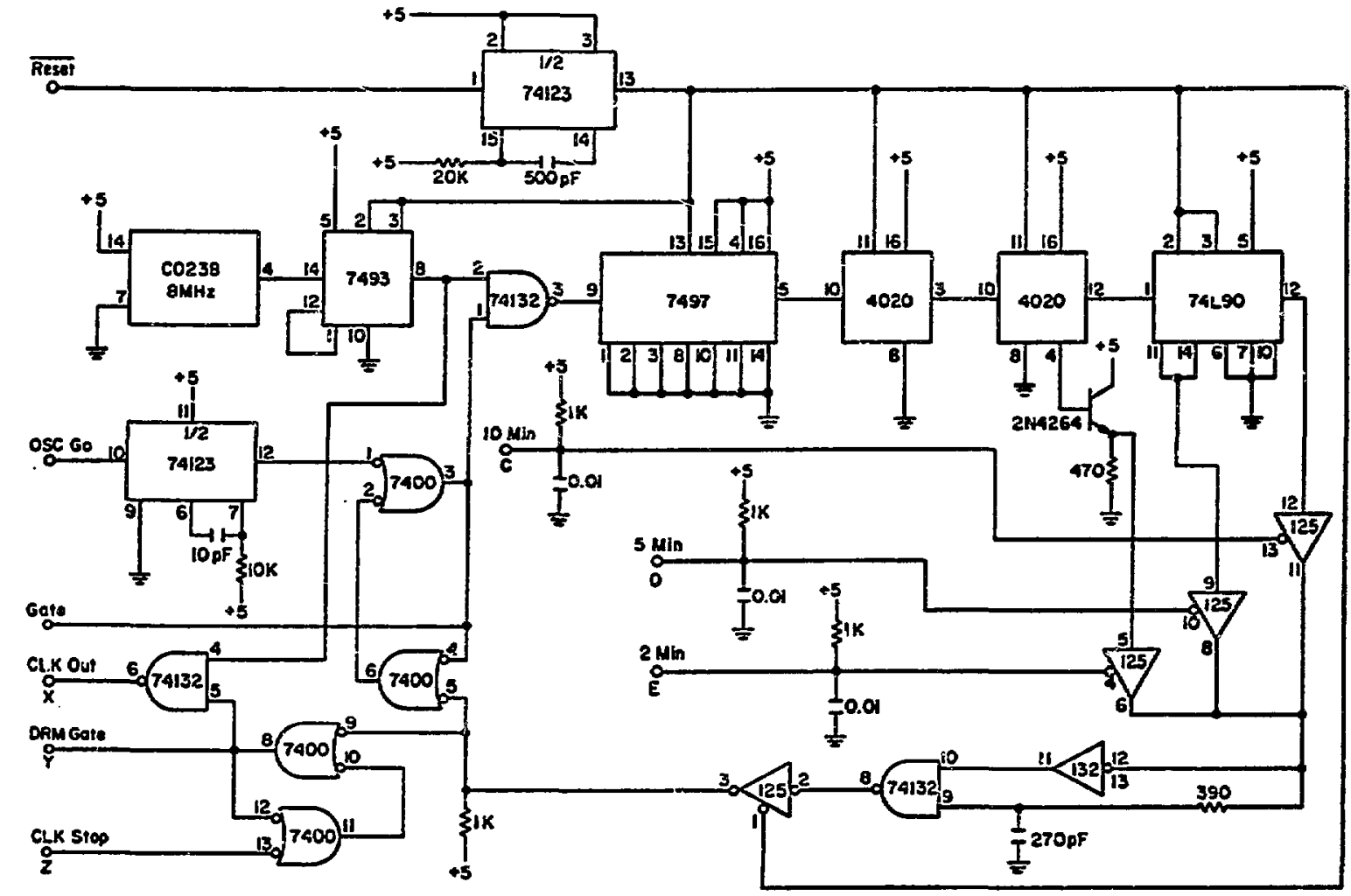

Fig. 13. Interval Timer.

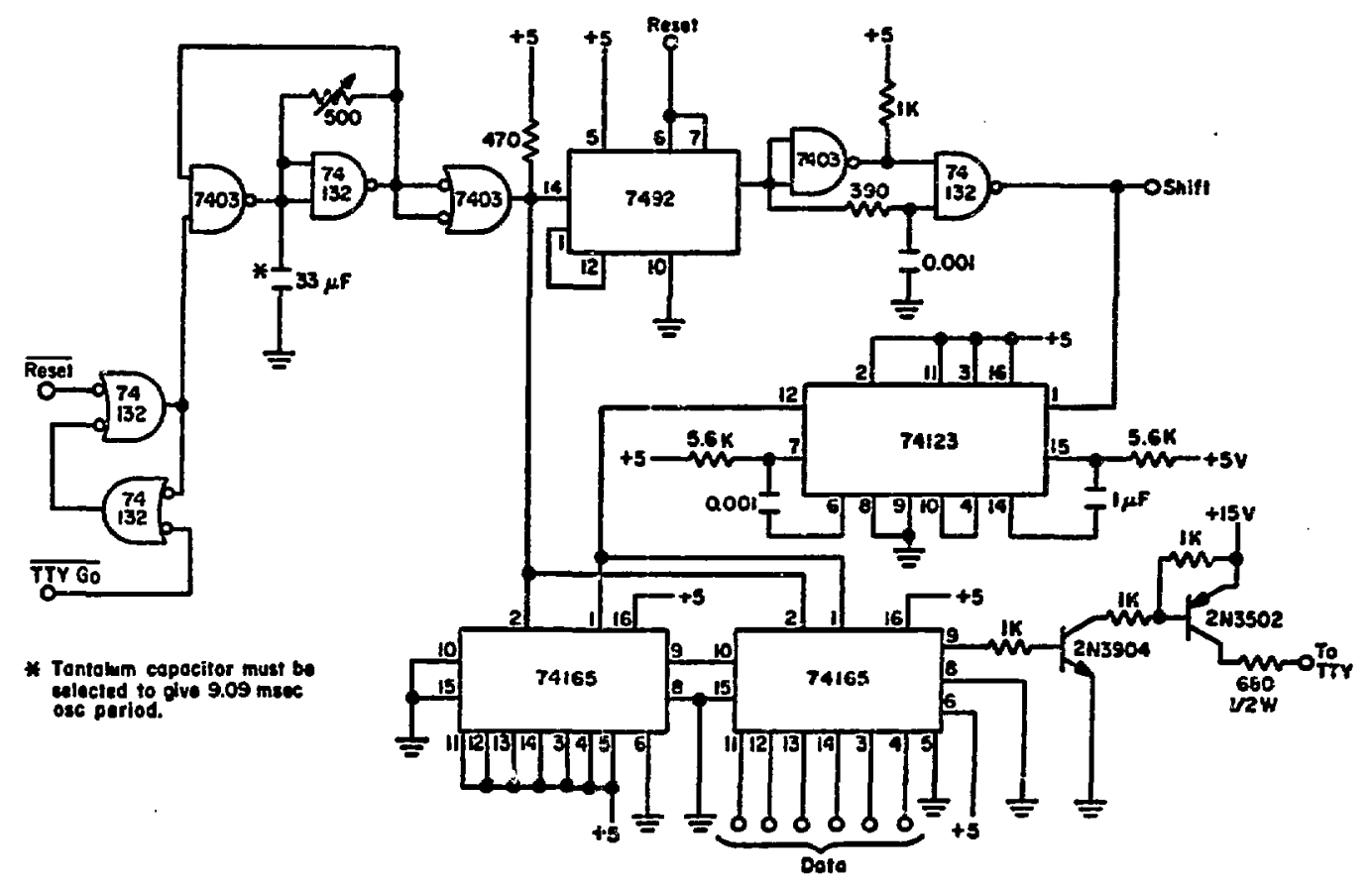

Fig. 14. Teletype Interface Board $\$ 1$. 


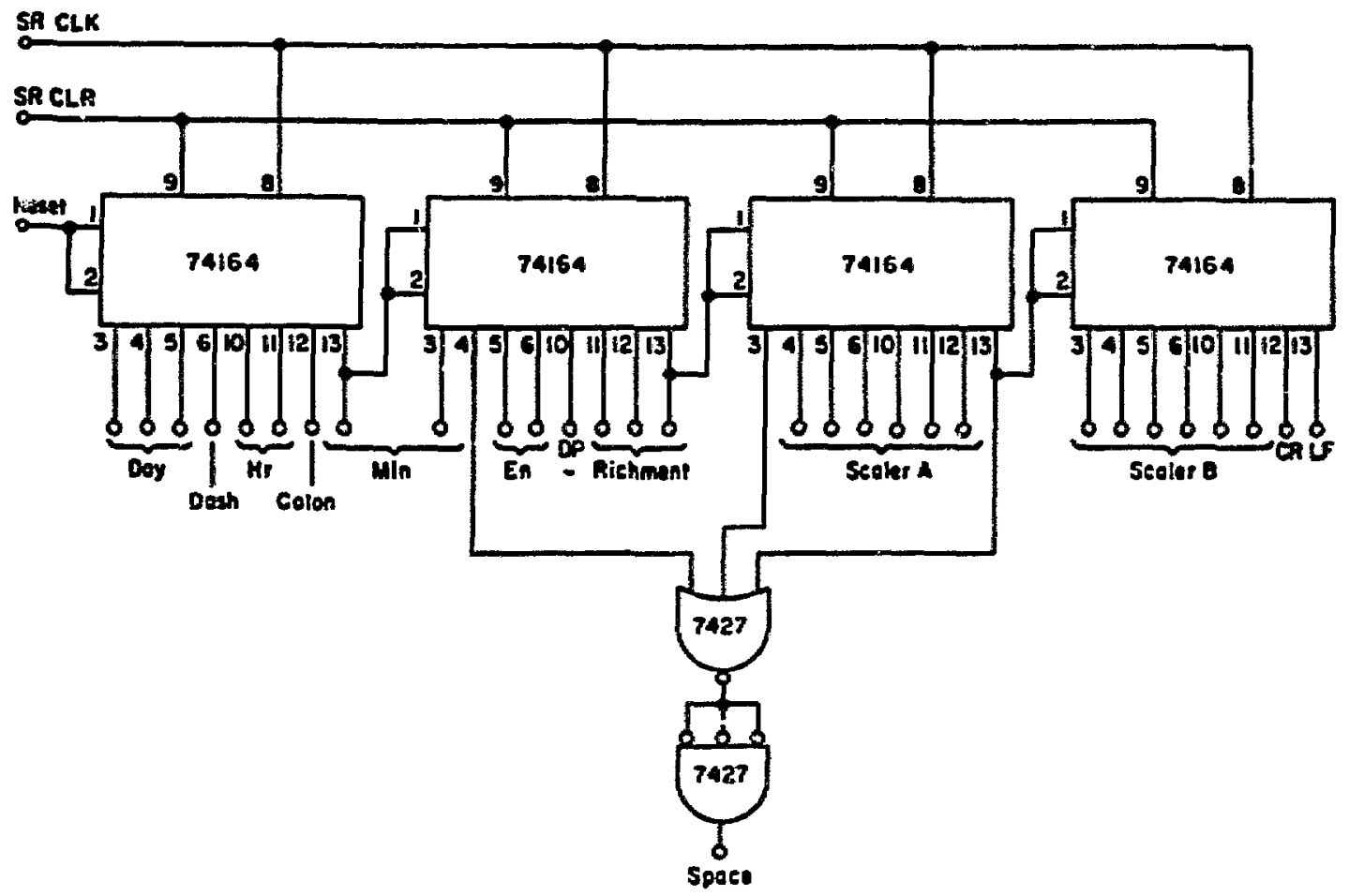

Fig. 15. Teletype Interface Bonrd $\$ 2$.

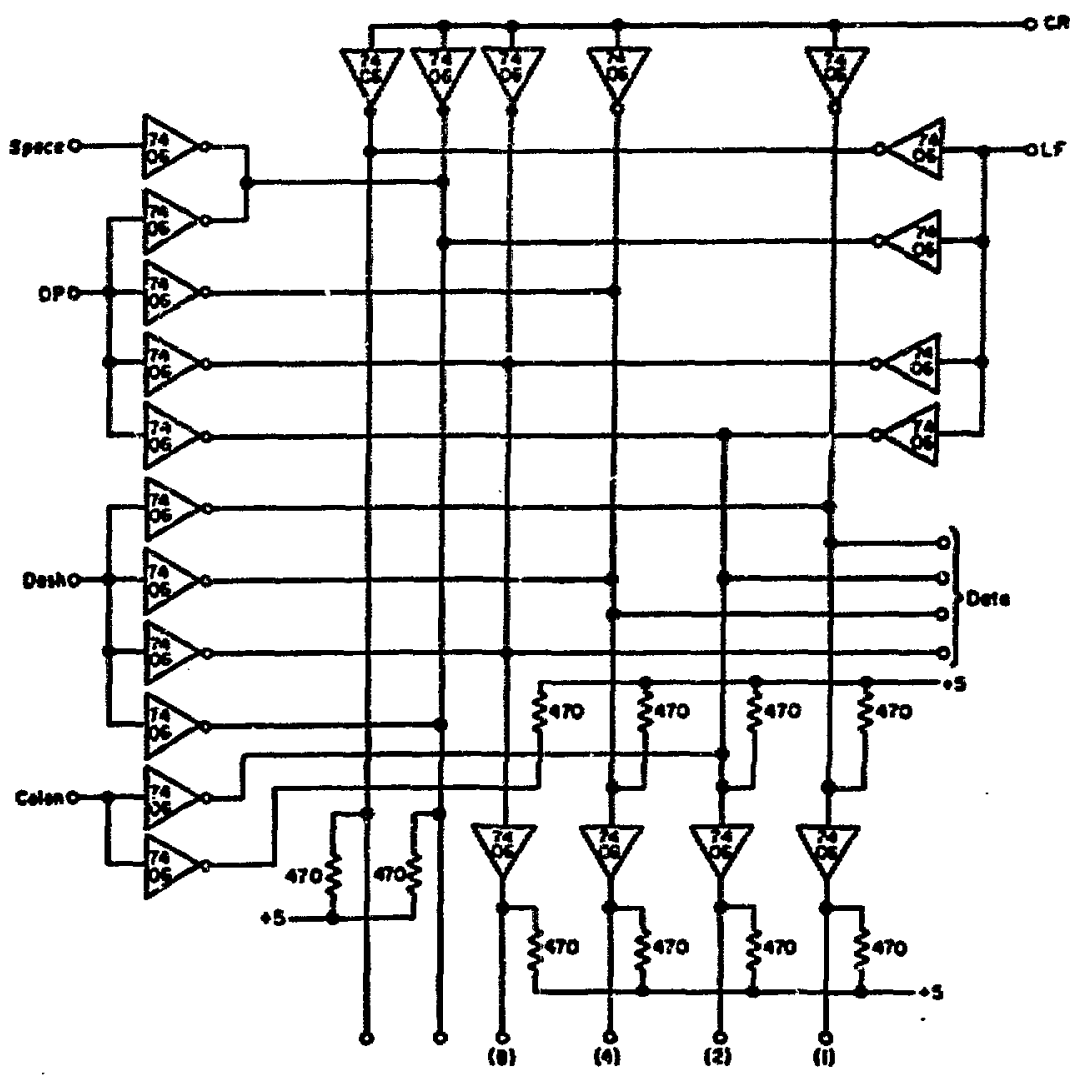

Fig. 16. Teletype interiece Data GateB. 